\title{
Simulating glacial lake outburst floods with a two-phase mass flow model
}

\author{
Parameshwari KATTEL, ${ }^{1,2}$ Khim B. KHATTRI, ${ }^{1}$ Puskar R. POKHREL, ${ }^{1,3}$ Jeevan KAFLE, $, 1,4$ \\ Bhadra Man TULADHAR, ${ }^{1}$ Shiva P. PUDASAINI ${ }^{5}$ \\ ${ }^{1}$ School of Science, Kathmandu University, Dhulikhel, Kavre, Nepal \\ ${ }^{2}$ Department of Mathematics, Tri-Chandra Multiple Campus, Tribhuvan University, Kathmandu, Nepal \\ ${ }^{3}$ Department of Mathematics, R.R. Campus, Tribhuvan University, Kathmandu, Nepal \\ ${ }^{4}$ Department of Mathematics, Valmiki Campus, Nepal Sanskrit University, Kathmandu, Nepal \\ ${ }^{5}$ Department of Geophysics, Steinmann Institute, University of Bonn, Bonn, Germany \\ Correspondence: Parameshwari Kattel <pkatte@student.ku.edu.np>
}

\begin{abstract}
To simulate a glacial lake outburst flood, we employ a comprehensive physically based general two-phase mass flow model (Pudasaini, 2012). This model accounts for a strong interaction between the solid and fluid phases and incorporates buoyancy and other dominant physical aspects of the mass flows such as enhanced non-Newtonian viscous stress, virtual mass force and generalized drag. Our real two-phase mass flow simulation describes explicit evolution of the solid and fluid phases and the debris bulk as a whole, akin to torrential debris flows or debris floods during glacial lake outburst floods (GLOFs). The emptying of a lake following rapid collapse of a restraining dam, the consequent downslope motion of a mixed solid-fluid mass, and the tendency of the mass to form extruding plumes are analyzed in detail for different flow configurations, volumes, conduit geometries and boundary conditions. The solid and fluid phases evolve completely differently and reveal fundamentally different dynamical behaviours. During the flow, the relatively long fluid tail follows the solid-rich dense frontal surge head. The bulk debris develops into a frontal and side levee as derived from the initial frontal moraine dam. Results show that our high-resolution, unified simulation strategies and the advanced model equations can be applied to study the flow dynamics of a wide range of geophysical mass flows such as snow and rock-ice avalanches, debris flows and flash floods as well as GLOFs. This may help substantially in forming a basis for appropriate mitigation measures against potential natural hazards in high mountain slopes and valleys.
\end{abstract}

KEYWORDS: applied glaciology, jökulhlaups (GLOFs)

\section{INTRODUCTION}

Mass wasting and mass flows are very important phenomena in process industries and geophysical events. Although different geophysical mass flows (e.g. landslides, debris flows, rockfalls, volcanic eruptions and flash floods) contribute substantially to landscape evolution, they may also cause tremendous damage to people and infrastructure. When loose masses of sediment saturated with water are disturbed due to instability, they may flow downslope in response to gravity, a phenomenon known as a debris flow (Iverson, 1997; Pitman and Le, 2005; Pudasaini and others, 2005; Pudasaini and Hutter, 2007). What distinguishes a debris flow from other mass flows is that both solid and fluid forces significantly influence the motion. The rapid motion, the density of the flow and especially the interactions between solid and fluid forces provide the debris flow with significant energy and destructive power, and a very long runout (Iverson, 1997; Pitman and Le, 2005; Pudasaini and Hutter, 2007; Fernandez-Nieto and others 2008; Pudasaini, 2012).

The retreat of glaciers may result in the formation and growth of glacial lakes dammed by moraines. Such dams may collapse causing glacial lake outburst floods (GLOFs) and resulting in massive and devastating debris flows (Pudasaini and Hutter, 2007; Breien and others, 2008; Lecomte and others, 2008; Awal and others, 2010; ICIMOD, 2011; Worni and others, 2012) (Fig. 1).
The evolving behaviour of a debris flow is very complex and therefore cannot be represented by a single rheological equation. In the past, various rheological models have been presented, but these are effectively single-phase models (e.g. viscoplastic continuum or Bingham model) (Johnson, 1965; Takahashi, 1991; Iverson, 1997). There have been significant fundamental research activities in the past few decades in the field of debris and similar mass flows, for example: (1) single-phase dry granular avalanches (Savage and Hutter, 1989; Hungr, 1995; Hutter and others, 1996; Gray and others, 1999; Pudasaini and Hutter, 2003); (2) single-phase debris flows (Bagnold, 1954; Chen, 1988; O'Brien and others, 1993; Takahashi, 2007); (3) mixture flows (Iverson, 1997; Iverson and Denlinger, 2001; Pudasaini and others, 2005); (4) two-fluid debris flow (Pitman and Le, 2005); and (5) a two-layered model (Fernandez-Nieto and others, 2008). Existing models have significant limitations and many assumptions are required to fit these extremely complex particle-fluid interacting flows (Cageao and others, 2013).

With a major advance in two-phase debris flow modelling and simulation, Pudasaini (2012) proposed a comprehensive theory and simulation technique (Pudasaini, 2012, 2014; Pudasaini and Krautblatter, 2014). The model accounts for interactions between the solid and fluid. It includes buoyancy and three other important and dominant 


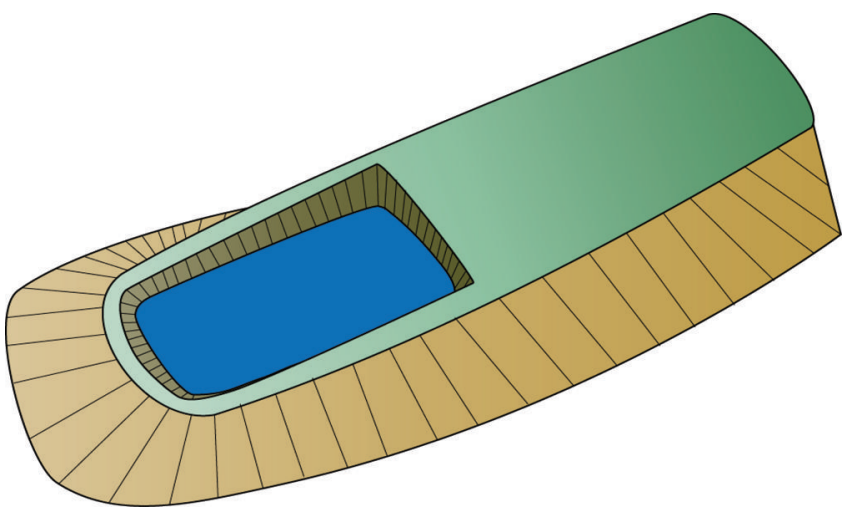

Fig. 1. Sketch of a moraine-dammed lake in a glaciated high mountain.

physical aspects of flow: (1) enhanced non-Newtonian viscous stress induced by changes in the volume fraction of solid; (2) virtual mass; and (3) generalized drag (Pudasaini, 2012). This model constitutes the most generalized twophase avalanche and debris flow model to date. The major physical aspects of the model are discussed briefly below.

Although fluid pressure and simple drag between the two phases have been included in some previous models (Iverson and Denlinger, 2001; Pitman and Le, 2005; Pudasaini and others, 2005), they lack three very important physical features that can be observed in real two-phase natural debris flows. (1) As the two phases have different velocities, they may also have relative accelerations. If the solid particles accelerate relative to the fluid, a part of the ambient fluid also accelerates, inducing a virtual mass force (the change in the kinetic energy of the fluid). Pudasaini (2012) was the first to incorporate the virtual mass force into debris flow dynamics. (2) Another important physical aspect included exclusively in the Pudasaini (2012) model is nonNewtonian viscous stress due to gradients in the volume fraction of solids. In fact, the quantity and gradient of the solid particles, which can either enhance or downplay viscous effects, influence the flow substantially. (3) In the Pudasaini model, the sedimentation velocity and terminal velocity of an isolated solid particle falling in a fluid, and the Kozeny-Carman packing of spheres, have been combined to form a new generalized drag coefficient that can be used for both linear and quadratic drags. As the material composition evolves in time and space in a real two-phase debris flow, leading to solid-dominated (more solid material than fluid) or fluid-dominated local regions in the same debris body, the drag forces in the debris flows can only be modelled and described properly by applying a generalized drag force (Pudasaini, 2012).

The two-phase debris flow model (Pudasaini, 2012) has been presented in a well-structured set of hyperbolicparabolic partial differential equations. In most studies to date, single-phase granular flows, or effectively single-phase debris flows, have been simulated for three-dimensional (3-D) topography (Gray and others, 1999; Iverson and Denlinger, 2001; Pudasaini and others, 2005; Pudasaini and Hutter, 2007) and two-phase flows have been simulated only in the downhill direction presenting the explicit evolution of the solid and the fluid components for both subaerial and submarine debris flows (Pudasaini, 2012). Here we present some novel and basic geometrically 3-D simulation results for flows of a real two-phase debris material down an inclined channel describing a rapidly cascading GLOF or a mountain tsunami. This includes different initial flow configurations, volumes, channel geometries and boundary conditions. Results are presented and discussed for flows down unconfined slopes, and slopes with laterally partially confined conduits of different types upstream and unconfined slopes downstream. This resulted in two flow types: fully unconstrained flows and laterally confined flows leading to lake emptying. More simulations with more complicated eigenvalues of the model system, the 3-D subaerial debris flows impacting a fluid reservoir and thus generating tsunami waves, and some exact solutions to a reduced model, can be found in Pokhrel (2014), Kafle (2014) and Khattri (2014), respectively. Differences in the flow of debris masses with different physical and material parameters have been described by Kattel (2014). For a mechanically enhanced approach to the modelling of rock-ice avalanches, we refer to Pudasaini and Krautblatter (2014), where the mass and momentum exchanges of the phases are also considered.

\section{MODELLING THE DYNAMICS OF TWO-PHASE DEBRIS FLOWS}

In a two-phase debris flow model, phases are characterized by their different material properties. The solid phase is characterized by its material density $\rho_{\mathrm{s}}$, internal friction angle $\phi$, basal friction angle $\delta$, an anisotropic stress distribution and the lateral earth pressure coefficients $K_{x}$ and $K_{y}$, whereas the fluid phase is characterized by its material density $\rho_{\mathrm{f}}$, viscosity $\eta_{\mathrm{f}}$ and an isotropic stress distribution. The subscripts $s$ and $f$ are for the solid and fluid phases, respectively. We assume that the flow depth $h$, the volume fraction of the fluid $\alpha_{\mathrm{f}}$ (or the solid $\alpha_{s}=1-\alpha_{\mathrm{f}}$ ), the depth-averaged velocity components for fluid $\mathbf{u}_{\mathrm{f}}=\left(u_{\mathrm{f}}, v_{\mathrm{f}}\right)$ and solid $\mathbf{u}_{\mathrm{s}}=\left(u_{\mathrm{s}}, v_{\mathrm{s}}\right)$ in the downslope $(x)$ and the crossslope $(y)$ directions, respectively, are to be computed as functions of space and time. Our simulation is based on the following two-phase debris flow model, locally integrated along the flow depth direction (Pudasaini, 2012):

$$
\begin{gathered}
\frac{\partial}{\partial t}\left(\alpha_{\mathrm{s}} h\right)+\frac{\partial}{\partial x}\left(\alpha_{\mathrm{s}} h u_{\mathrm{s}}\right)+\frac{\partial}{\partial y}\left(\alpha_{\mathrm{s}} h v_{\mathrm{s}}\right)=0, \\
\frac{\partial}{\partial t}\left(\alpha_{\mathrm{f}} h\right)+\frac{\partial}{\partial x}\left(\alpha_{\mathrm{f}} h u_{\mathrm{f}}\right)+\frac{\partial}{\partial y}\left(\alpha_{\mathrm{f}} h v_{\mathrm{f}}\right)=0,
\end{gathered}
$$

$$
\begin{aligned}
& \frac{\partial}{\partial t}\left[\alpha_{\mathrm{s}} h\left(u_{\mathrm{s}}-\gamma \mathcal{C}\left(u_{\mathrm{f}}-u_{\mathrm{s}}\right)\right)\right]+\frac{\partial}{\partial x}\left[\alpha_{\mathrm{s}} h\left(u_{\mathrm{s}}^{2}-\gamma \mathcal{C}\left(u_{\mathrm{f}}^{2}-u_{\mathrm{s}}^{2}\right)+\frac{\beta_{x_{\mathrm{s}}} h}{2}\right)\right] \\
& +\frac{\partial}{\partial y}\left[\alpha_{\mathrm{s}} h\left(u_{\mathrm{s}} v_{\mathrm{s}}-\gamma \mathcal{C}\left(u_{\mathrm{f}} v_{\mathrm{f}}-u_{\mathrm{s}} v_{\mathrm{s}}\right)\right)\right]=h S_{\mathrm{x}_{\mathrm{s}}}
\end{aligned}
$$

$$
\begin{gathered}
\frac{\partial}{\partial t}\left[\alpha_{\mathrm{s}} h\left(v_{\mathrm{s}}-\gamma \mathcal{C}\left(v_{\mathrm{f}}-v_{\mathrm{s}}\right)\right)\right]+\frac{\partial}{\partial x}\left[\alpha_{\mathrm{s}} h\left(u_{\mathrm{s}} v_{\mathrm{s}}-\gamma \mathcal{C}\left(u_{\mathrm{f}} v_{\mathrm{f}}-u_{\mathrm{s}} v_{\mathrm{s}}\right)\right)\right] \\
+\frac{\partial}{\partial y}\left[\alpha_{\mathrm{s}} h\left(v_{\mathrm{s}}^{2}-\gamma \mathcal{C}\left(v_{\mathrm{f}}^{2}-v_{\mathrm{s}}^{2}\right)+\frac{\beta_{y_{\mathrm{s}}} h}{2}\right)\right]=h S_{y_{\mathrm{s}}}
\end{gathered}
$$

$$
\begin{aligned}
& \frac{\partial}{\partial t}\left[\alpha_{\mathrm{f}} h\left(u_{\mathrm{f}}+\frac{\alpha_{\mathrm{s}}}{\alpha_{\mathrm{f}}} \mathcal{C}\left(u_{\mathrm{f}}-u_{\mathrm{s}}\right)\right)\right]+\frac{\partial}{\partial x}\left[\alpha_{\mathrm{f}} h\left(u_{\mathrm{f}}^{2}+\frac{\alpha_{\mathrm{s}}}{\alpha_{\mathrm{f}}} \mathcal{C}\left(u_{\mathrm{f}}^{2}-u_{\mathrm{s}}^{2}\right)+\frac{\beta_{x_{\mathrm{f}}} h}{2}\right)\right] \\
& +\frac{\partial}{\partial y}\left[\alpha_{\mathrm{f}} h\left(u_{\mathrm{f}} v_{\mathrm{f}}+\frac{\alpha_{\mathrm{s}}}{\alpha_{\mathrm{f}}} \mathcal{C}\left(u_{\mathrm{f}} v_{\mathrm{f}}-u_{\mathrm{s}} v_{\mathrm{s}}\right)\right)\right]=h S_{x_{\mathrm{f}}}
\end{aligned}
$$




$$
\begin{aligned}
& \frac{\partial}{\partial t}\left[\alpha_{\mathrm{f}} h\left(v_{\mathrm{f}}+\frac{\alpha_{\mathrm{s}}}{\alpha_{\mathrm{f}}} \mathcal{C}\left(v_{\mathrm{f}}-v_{\mathrm{s}}\right)\right)\right]+\frac{\partial}{\partial x}\left[\alpha_{\mathrm{f}} h\left(u_{\mathrm{f}} v_{\mathrm{f}}+\frac{\alpha_{\mathrm{s}}}{\alpha_{\mathrm{f}}} \mathcal{C}\left(u_{\mathrm{f}} v_{\mathrm{f}}-u_{\mathrm{s}} v_{\mathrm{s}}\right)\right)\right] \\
& +\frac{\partial}{\partial y}\left[\alpha_{\mathrm{f}} h\left(v_{\mathrm{f}}^{2}+\frac{\alpha_{\mathrm{s}}}{\alpha_{\mathrm{f}}} \mathcal{C}\left(v_{\mathrm{f}}^{2}-v_{\mathrm{s}}^{2}\right)+\frac{\beta_{y_{\mathrm{f}}} h}{2}\right)\right]=h S_{y_{\mathrm{f}},}
\end{aligned}
$$

in which

$$
\begin{aligned}
& \beta_{x_{\mathrm{s}}}=\varepsilon K_{x} p_{b_{\mathrm{s}}}, \quad \beta_{y_{\mathrm{s}}}=\varepsilon K_{y} p_{b_{\mathrm{s}}} \\
& \beta_{x_{\mathrm{f}}}=\beta_{y_{\mathrm{f}}}=\varepsilon p_{b_{\mathrm{f}}}, \quad p_{b_{\mathrm{f}}}=-g^{z}, \quad p_{b_{\mathrm{s}}}=(1-\gamma) p_{b_{\mathrm{f}}} .
\end{aligned}
$$

Equations (1) and (2) are the depth-averaged mass balances for solid and fluid phases, respectively, and the last four equations are the depth-averaged momentum balances for solid (Eqns (3) and (4)) and fluid (Eqns (5) and (6)) in the $x$ and $y$ directions, respectively. The source terms are given by Pudasaini (2012):

$$
\begin{aligned}
& S_{x_{\mathrm{s}}}=\alpha_{\mathrm{s}}\left[g^{x}-p_{b_{\mathrm{s}}}\left(\frac{u_{\mathrm{s}}}{\left|\mathbf{u}_{\mathrm{s}}\right|} \tan \delta+\varepsilon \frac{\partial b}{\partial x}\right)\right] \\
& -\varepsilon \alpha_{\mathrm{s}} \gamma p_{b_{\mathrm{f}}}\left[\frac{\partial h}{\partial x}+\frac{\partial b}{\partial x}\right]+C_{\mathrm{DG}}\left(u_{\mathrm{f}}-u_{\mathrm{s}}\right)\left|\mathbf{u}_{\mathrm{f}}-\mathbf{u}_{\mathrm{s}}\right|^{\prime-1}, \\
& S_{y_{\mathrm{s}}}=\alpha_{\mathrm{s}}\left[g^{y}-p_{b_{\mathrm{s}}}\left(\frac{v_{\mathrm{s}}}{\left|\mathbf{u}_{\mathrm{s}}\right|} \tan \delta+\varepsilon \frac{\partial b}{\partial y}\right)\right] \\
& -\varepsilon \alpha_{\mathrm{s}} \gamma p_{b_{\mathrm{f}}}\left[\frac{\partial h}{\partial y}+\frac{\partial b}{\partial y}\right]+C_{\mathrm{DG}}\left(v_{\mathrm{f}}-v_{\mathrm{s}}\right)\left|\mathbf{u}_{\mathrm{f}}-\mathbf{u}_{\mathrm{s}}\right|^{j-1}, \\
& S_{x_{\mathrm{f}}}=\alpha_{\mathrm{f}}\left[g^{x}-\varepsilon\left[\frac{1}{2} p_{b_{\mathrm{f}}} \frac{h}{\alpha_{\mathrm{f}}} \frac{\partial \alpha_{\mathrm{s}}}{\partial x}+p_{b_{\mathrm{f}}} \frac{\partial b}{\partial x}-\frac{1}{\alpha_{\mathrm{f}} N_{\mathrm{R}}}\right.\right. \\
& \left\{2 \frac{\partial^{2} u_{\mathrm{f}}}{\partial x^{2}}+\frac{\partial^{2} v_{\mathrm{f}}}{\partial y \partial x}+\frac{\partial^{2} u_{\mathrm{f}}}{\partial y^{2}}-\frac{\chi u_{\mathrm{f}}}{\varepsilon^{2} h^{2}}\right\}+\frac{1}{\alpha_{\mathrm{f}} N_{\mathrm{R}_{\mathcal{A}}}} \\
& \left\{2 \frac{\partial}{\partial x}\left(\frac{\partial \alpha_{\mathrm{s}}}{\partial x}\left(u_{\mathrm{f}}-u_{\mathrm{s}}\right)\right)+\frac{\partial}{\partial y}\left(\frac{\partial \alpha_{\mathrm{s}}}{\partial x}\left(v_{\mathrm{f}}-v_{\mathrm{s}}\right)+\frac{\partial \alpha_{\mathrm{s}}}{\partial y}\left(u_{\mathrm{f}}-u_{\mathrm{s}}\right)\right)\right\} \\
& \left.\left.-\frac{\xi \alpha_{\mathrm{s}}\left(u_{\mathrm{f}}-u_{\mathrm{s}}\right)}{\varepsilon^{2} \alpha_{\mathrm{f}} N_{\mathrm{R}_{\mathcal{A}}} h^{2}}\right]\right]-\frac{1}{\gamma} C_{\mathrm{DG}}\left(u_{\mathrm{f}}-u_{\mathrm{s}}\right)\left|\mathbf{u}_{\mathrm{f}}-\mathbf{u}_{\mathrm{s}}\right|^{j-1}, \\
& S_{y_{\mathrm{f}}}=\alpha_{\mathrm{f}}\left[g^{y}-\varepsilon\left[\frac{1}{2} p_{b_{\mathrm{f}}} \frac{h}{\alpha_{\mathrm{f}}} \frac{\partial \alpha_{\mathrm{s}}}{\partial y}+p_{b_{\mathrm{f}}} \frac{\partial b}{\partial y}-\frac{1}{\alpha_{\mathrm{f}} N_{\mathrm{R}}}\right.\right. \\
& \left\{2 \frac{\partial^{2} v_{f}}{\partial y^{2}}+\frac{\partial^{2} u_{f}}{\partial x \partial y}+\frac{\partial^{2} v_{f}}{\partial x^{2}}-\frac{\chi v_{f}}{\varepsilon^{2} h^{2}}\right\}+\frac{1}{\alpha_{f} N_{R_{\mathcal{A}}}} \\
& \left\{2 \frac{\partial}{\partial y}\left(\frac{\partial \alpha_{\mathrm{s}}}{\partial y}\left(v_{\mathrm{f}}-v_{\mathrm{s}}\right)\right)+\frac{\partial}{\partial x}\left(\frac{\partial \alpha_{\mathrm{s}}}{\partial y}\left(u_{\mathrm{f}}-u_{\mathrm{s}}\right)+\frac{\partial \alpha_{\mathrm{s}}}{\partial x}\left(v_{\mathrm{f}}-v_{\mathrm{s}}\right)\right)\right\} \\
& \left.\left.-\frac{\xi \alpha_{\mathrm{s}}\left(v_{\mathrm{f}}-v_{\mathrm{s}}\right)}{\varepsilon^{2} \alpha_{\mathrm{f}} N_{\mathrm{R}_{\mathcal{A}}} h^{2}}\right]\right]-\frac{1}{\gamma} C_{\mathrm{DG}}\left(v_{\mathrm{f}}-v_{\mathrm{s}}\right)\left|\mathbf{u}_{\mathrm{f}}-\mathbf{u}_{\mathrm{s}}\right|^{J-1}
\end{aligned}
$$

where

$$
\begin{aligned}
C_{\mathrm{DG}} & =\frac{\alpha_{\mathrm{s}} \alpha_{\mathrm{f}}(1-\gamma)}{\left[\mathcal{E} \mathcal{U}_{T}\left\{\mathcal{P} \mathcal{F}\left(R e_{\mathrm{p}}\right)+(1-\mathcal{P}) \mathcal{G}\left(R e_{\mathrm{p}}\right)\right\}\right]^{\prime}}, \gamma=\frac{\rho_{\mathrm{f}}}{\rho_{\mathrm{s}}}, \\
\mathcal{F} & =\frac{\gamma}{180}\left(\frac{\alpha_{\mathrm{f}}}{\alpha_{\mathrm{s}}}\right)^{3} \operatorname{Re}_{\mathrm{p}}, \mathcal{G}=\alpha_{\mathrm{f}}^{M\left(R e_{\mathrm{p}}\right)-1}, R e_{\mathrm{p}}=\frac{\rho_{\mathrm{f}} d \mathcal{U}_{\mathrm{T}}}{\eta_{\mathrm{f}}}, \\
N_{\mathrm{R}} & =\frac{\sqrt{g L} H \rho_{\mathrm{f}}}{\alpha_{\mathrm{f}} \eta_{\mathrm{f}}}, \quad N_{\mathrm{R}_{\mathcal{A}}}=\frac{\sqrt{g L} H \rho_{\mathrm{f}}}{\mathcal{A} \eta_{f}} .
\end{aligned}
$$

In Eqns (1-11), $x, y$ and $z$ are coordinates along the downslope flow direction, cross-wise direction and the direction perpendicular to the flow surface (Fig. 2, inset), respectively; $g^{x}, g^{y}$ and $g^{z}$ are the components of gravitational acceleration; $\varepsilon=H / L$ is the aspect ratio, where $L$ and $H$ are the typical length and depth of the flow; $\mu=\tan \delta$ is the basal friction coefficient; $C_{D G}$ is the generalized drag coefficient; $J=1$ or 2 represents linear (laminar-type) or quadratic (turbulent-type) drag; $\mathcal{U}_{\mathrm{T}}$ is the terminal velocity of a particle; $\mathcal{P}$, which takes values between 0 and 1 , is a parameter that combines the solid-like $(\mathcal{G})$ and fluid-like $(\mathcal{F})$ drag contributions to flow resistance; $p_{b_{f}}$ and $p_{b_{s}}$ are the effective fluid and solid pressures; $\gamma$ is the density ratio; $\mathcal{C}$ is the virtual mass coefficient; $M$ is a function of the particle Reynolds number $\left(R e_{p}\right) ; \chi$ includes vertical shearing of fluid velocity; $\xi$ takes into account different distributions of $\alpha_{\mathrm{s}}$; $\mathcal{A}=\mathcal{A}\left(\alpha_{\mathrm{f}}\right)$ is the mobility of the fluid at the interface; $N_{\mathrm{R}}$ is a quasi-Reynolds number; and $N_{R_{\mathcal{A}}}$ is a mobility Reynolds number associated with the classical Newtonian and enhanced non-Newtonian fluid viscous stresses, respectively.

Since the undisturbed flows down the smooth basal surface are thin with large lateral extents, the depthaveraged mass and momentum equations are often used in simulating geophysical mass flows (Gray and others, 1999; Iverson and Denlinger, 2001; Pitman and Le, 2005; Pudasaini and Hutter, 2007; Pudasaini and Miller, 2013). Some physically justified assumptions are made to derive the momentum equations (Eqns (3-6)). These assumptions include Mohr-Coulomb plastic deformation for the solid, and enhanced non-Newtonian viscous deformation for the fluid phase. As the material in the GLOF consists of solid particles with internal and basal frictions, together with viscous fluid, there are strong phase interactions. Such interactions are modelled here with the interfacial momentum transfer which includes the viscous drag on the particulate phase and the virtual mass force induced by the relative acceleration between the phases that alters the kinetic energy of the fluid phase. The viscous drag also evolves as a function of particle concentration and several physical parameters of the mixture. This results in solid-like drag on particles moving in a more dilute fluid or fluid-like drag for the fluid passing through a relatively densely packed granular matrix. Furthermore, the effective fluid shear stress is enhanced by the particle concentration distribution, and the solid particle concentration can decrease or increase during the flow, resulting in mixing or separation of the phases (Pudasaini, 2012). This discussion justifies the need for the use of a real two-phase mass flow model for an evolving mixture of solid particles and viscous fluid to model the dynamics of GLOFs.

With the material parameters mentioned above and the basal topography $b=b(x, y)$, Eqns (1-6) allow the computation of debris flow depth $h$, volume fraction of the fluid $\alpha_{\mathrm{f}}$ (or solid $\alpha_{\mathrm{s}}$ ), and the depth-averaged velocity components for solid $\left(u_{\mathrm{s}}\right.$ and $\left.v_{\mathrm{s}}\right)$ and fluid $\left(u_{\mathrm{f}}\right.$ and $v_{\mathrm{f}}$ ) parallel to the basal surface as functions of space and time, once appropriate initial and boundary conditions are provided.

\section{SIMULATION RESULTS AND DISCUSSION}

Here we present some basic simulations representing scenarios akin to GLOFs. The simulations are novel because they are based on the general two-phase mass flow model (Pudasaini, 2012) and present explicit and simultaneous evolutions of the solid phase, fluid phase and total debris (mass) as a whole.

\subsection{Simulation set-ups}

We consider three different initial 3-D triangular-wedged glacial lakes supported by saturated frontal moraine dams: (1) idealized weak rectangular lateral walls that virtually collapse during the mass release; (2) solid almost vertical $\left(85^{\circ}\right)$ lateral walls forming a relatively long rectangular 


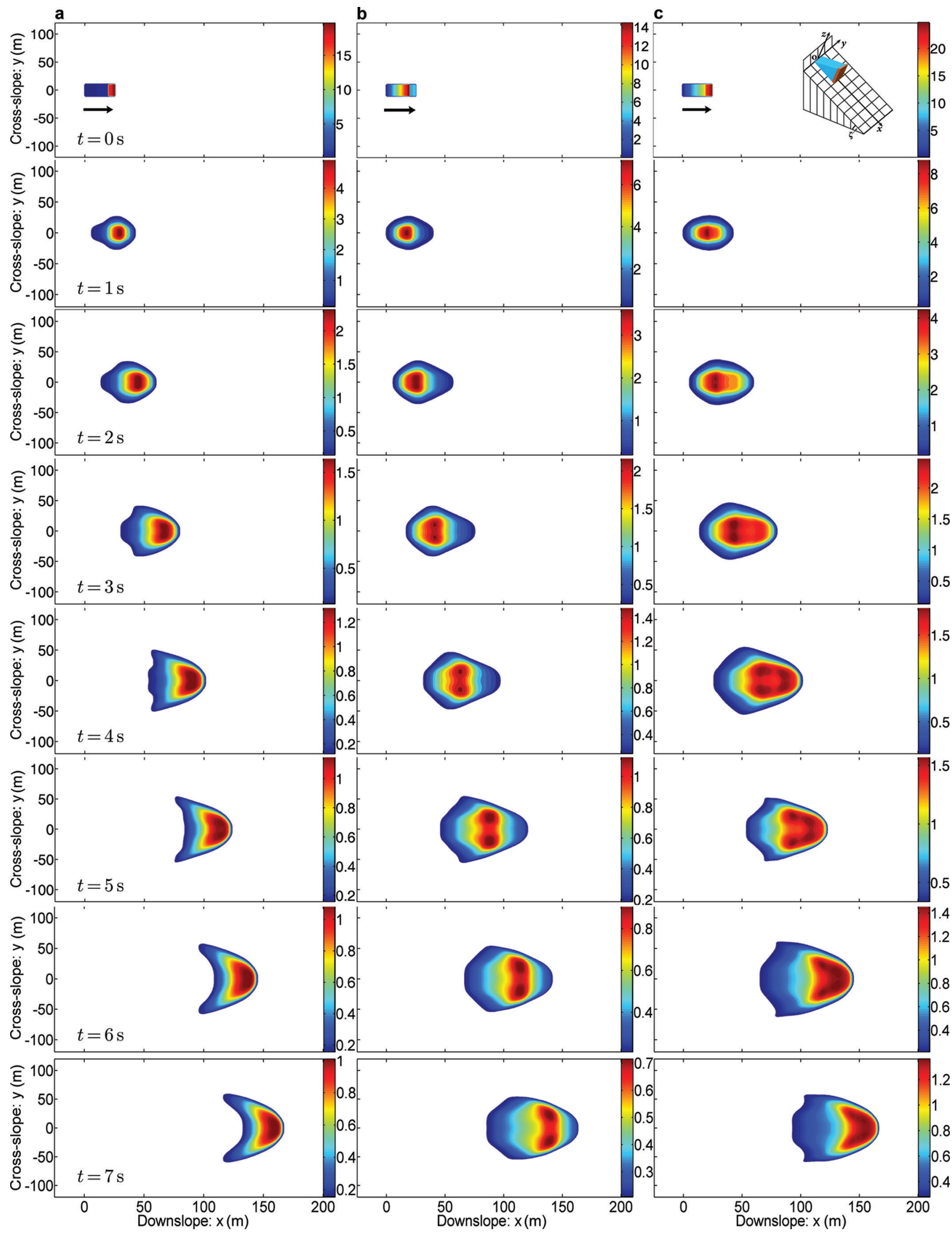

Fig. 2. Rectangular virtual lateral walls: evolution of (a) solid phase, (b) fluid phase and (c) total debris mixture at $t=0,1,2,3,4,5,6$ and $7 \mathrm{~s}$ as the moraine dam $(20 \mathrm{~m} \leq x \leq 25 \mathrm{~m})$ breaks off, triggering a GLOF. The solid and fluid phases evolve completely differently and reveal fundamentally different dynamical behaviours. The main solid part of the debris mixture moves much more ahead than the fluid phase. The colour bars show that the position and the depth of the maxima change as time progresses. Due to the phase evolutions, the maximum and minimum are changing in each panel. The arrows in the top panels indicate the flow direction. Inset in top panel of (c) shows the simulation set-up for a 3-D and two-phase mass moving down an inclined surface. The triangular cap indicates the initial debris mass. 
channel upstream (akin to lateral mountain slopes) that prevent lateral spreading during the mass collapse and outbursts for a substantial downstream distance including the dam and the lake; and (3) a fan-type laterally expanding lake with upslope widening triangular lateral walls representing a more realistic situation than (1) and (2). Configuration 3 also prevents the lateral mass spreading during the emptying of the lake and diverts the debris into the central line of the slope. Here we analyze in detail the influence of initial channel geometry, material volume and boundary conditions on the initial stages of the outburst floods and the subsequent dynamic evolution of GLOFs. The simulation set-ups as given in the insets of Figures 2-4 represent idealized inclined mountain flanks and channels.

\subsection{Parameter choice and numerical method}

The non-dimensional parameters chosen for simulation are: $\phi=35^{\circ}, \delta=15^{\circ}, \mathcal{U}_{\top}=1.0, \operatorname{Re}_{\mathrm{p}}=1, \chi=0, \xi=0, \mathcal{P}=0.5, J=1$ (only linear drag), $\mathcal{C}=0.5, N_{R}=30000$ and $N_{R_{A}}=1000$. The inclination angle for the flow surface is $\zeta=45^{\circ}$. As discussed in Pudasaini $(2012,2014)$ and Pudasaini and Krautblatter (2014), these parameter selections are based on the physics of two-phase subaerial and submarine mass flows. In a geophysical mass flow, there is generally rapid motion, large deformations and abrupt changes in flow dynamical variables. In order to capture such complex phenomena, we employ high-resolution total variation diminishing (TVD) non-oscillatory central (NOC) schemes (Nessyahu and Tadmor, 1990; Pudasaini and Hutter, 2007) to numerically integrate the model Eqns (1-6). The number of simulation gridpoints in the $x$ and $y$ directions is 501 and 101, respectively. With this, we can simulate relatively longer downslope distance. The Courant-Friedrichs-Lewy (CFL) number is 0.05 . The computational time for each simulation is typically on the order of $10 \mathrm{~min}$ on a PC.

\subsection{Descriptions of the results}

\subsubsection{Rectangular virtual lateral walls}

For the first simulation (Fig. 2), the glacial lake is defined by a triangular wedge $0 \mathrm{~m} \leq x \leq 25 \mathrm{~m},-10 \mathrm{~m} \leq y \leq 10 \mathrm{~m}$. In $20 \mathrm{~m} \leq x \leq 25 \mathrm{~m}$, there is a partially saturated (80\% solid, $20 \%$ fluid) moraine dam restraining the lake (or reservoir), which contains $95 \%$ viscous fluid and $5 \%$ solid grains. The fluid level in the lake is reduced by $20 \%$ with respect to the frontal moraine dam to withstand the weight of fluid. Initially, the lake is controlled by two lateral virtual walls. The simulation is carried out by adding (on the right-hand side of Eqn (7)) a nominal bulk viscous drag (Pudasaini and Hutter, 2007) $0.01 \alpha_{\mathrm{s}} u_{\mathrm{s}}\left(u_{\mathrm{s}}^{2}+v_{\mathrm{s}}^{2}\right)^{0.5}$ in the $x$ direction for the solid phase and similarly in the $y$ direction, and also for the fluid phase. This influences the dynamics of the solid; however, the fluid dynamics remain unaffected.

At $t=0 \mathrm{~s}$, the dam and the lateral virtual walls collapse (by letting the lake and the dam begin to deform and move under the action of gravity and pressure gradient), thereby generating a GLOF. Figure 2 describes the time evolution $(t=0,1,2,3,4,5,6,7 \mathrm{~s})$ of the solid depth, fluid depth and (total) debris flow depth.

We first analyze the flow of the solid phase as given in Figure 2a. As soon as the debris mass collapses at $t=0 \mathrm{~s}$, the solid at the front and at the back advects and disperses in the downstream and also significantly in the cross-stream direction. At the instant of moraine dam collapse, the fluid
- just behind the dam at the central line $(y=0)$ - has the highest hydrostatic pressure. This pressure and the gravity load strongly push the moraine dam, thereby strongly laterally deflecting the solid mass. This is evident from time $t>2 \mathrm{~s}$ and the deflection is more pronounced as time elapses. This results $(t=5 \mathrm{~s})$ in a cone-shaped laterally curved side levee and a frontal surge of the solid phase. The solid deflection is also coupled with the fluid, resulting in deflection of the fluid in the opposite direction. At $t=2 \mathrm{~s}$ (Fig. 2a), the relative maximum of the solid phase lies in the middle to frontal part of the debris body. The frontal part of the solid mass reaches a downslope distance of $60 \mathrm{~m}$, whereas the maximum height for fluid lies slightly beyond $30 \mathrm{~m}$. The advection, dispersion and deflection of the solid phase (and also of the fluid) continue at $t=3 \mathrm{~s}$ and later times. The frontal part still advects, but there is substantial spreading of the rear edge, which is mixed with the viscous fluid. The lateral spreading of the rear part is more pronounced at $t=4 \mathrm{~s}$, whereas the relative maximum of the solid phase lies on the frontal part from 80 to $100 \mathrm{~m}$. The colour bar on Figure 2 shows that the maximum height decreases continuously. From $t=4$ to $t=7 \mathrm{~s}$, the solid mass shows a typical shape of a reverse-barchan dune (Pudasaini and others, 2005). The tail of the solid mass completely disappears at $t=5 \mathrm{~s}$. By $t=7 \mathrm{~s}$, the solid mass has travelled nearly $165 \mathrm{~m}$ with a mean velocity of $\sim 25 \mathrm{~m} \mathrm{~s}^{-1}$, thereby generating a high impact force on any obstacle in its way. Note that, due to the evolution of the solid and the fluid phases, the maximum and the minimum values change in each panel in Figure 2.

Next we analyze the dynamics of the fluid flow (Fig. 2b). When the debris mass collapses, the fluid also spreads crosswise and advects in the downstream direction. At $t=1 \mathrm{~s}$, the maximum depth lies in the middle to rear part of the fluid phase. The lateral spreading of the fluid (mass) is substantial in the middle part at $t=2 \mathrm{~s}$. The frontal head is elongated; but, at the same time as for the solid (Fig. 2a), the rear is also elongated. The advection of the fluid is less than that of the solid, because the frontal solid-rich head hinders the flow of the fluid in the downstream direction. At $t=3$ and $4 \mathrm{~s}$, advection and dispersion continue in the same way.

Two relative maxima appear in the middle to frontal part of the fluid phase at $t=3 \mathrm{~s}$. This can be explained because the fluid motion is controlled by the dynamics of the tail of solid in the front. This exerts internal pressure on the fluid and results in two weakly separated fluid maxima. From $t=5$ to $t=7 \mathrm{~s}$, the fluid front widens slightly due to the continuous and strong deflection of the solid phase and the accelerating tail of the fluid. This results in the further separation of the local maxima.

Evolution of the total debris depth is dynamically more important. Figure 2c shows the sum of the solid and fluid phases (mass) as given in Figure 2a and b. As soon as the debris mass collapses, the total debris bulk disperses in all directions, but mainly downslope. Due to the fluid-rich tail of larger volume, from $t=1$ to $t=3 \mathrm{~s}$ the relative maximum lies in the middle to rear part. But, from $t=4$ to $t=7 \mathrm{~s}$, the relative maxima are mainly formed by the solid-rich frontal surge head. On the other hand, the maximum of the fluid surge follows the maximum of the solid. Consequently a strong frontal and lateral solid-rich levee forms, followed by fluid-rich secondary surges in the total debris depth evolution spanning from the frontal to middle part of the total debris body. In other words, there is an elongated and 


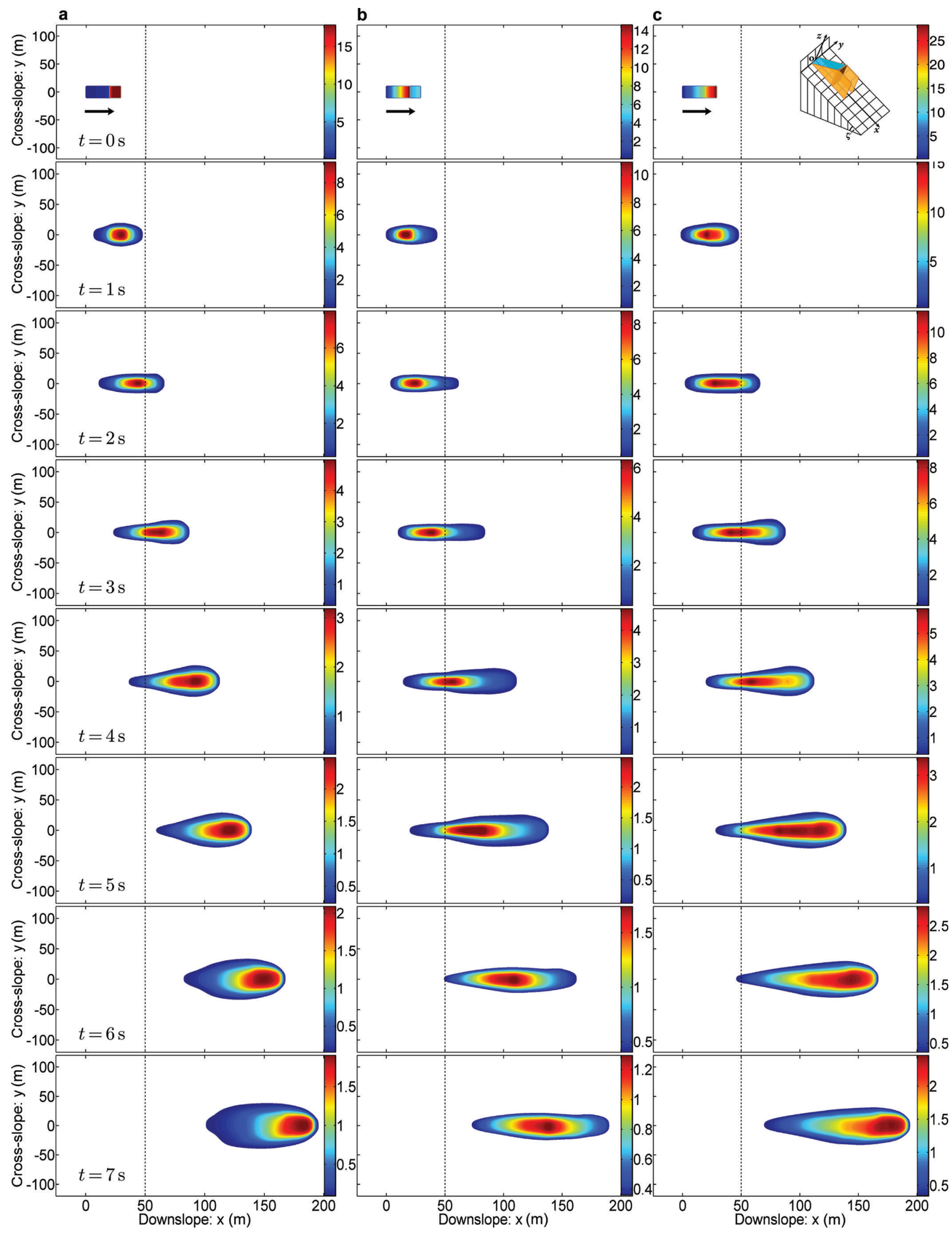

Fig. 3. Rectangular solid lateral walls: evolution of (a) solid phase, (b) fluid phase and (c) total debris mixture at $t=0,1,2,3,4,5,6$ and $7 \mathrm{~s}$ as a relatively longer moraine dam $(20 \mathrm{~m} \leq x \leq 29 \mathrm{~m})$ breaks and flow is accelerated in the laterally confined rectangular channel conduit $(29 \mathrm{~m} \leq x \leq 50 \mathrm{~m})$. The dashed line at $x=50 \mathrm{~m}$ indicates the conduit exit. As the debris material continues to exit the conduit, it develops continuously into a more pronounced, longitudinally elongated extruding debris plume which also expands laterally. The maxima of the solid and fluid phases evolve differently. The arrows in the top panels indicate the flow direction. Inset in top panel of (c) shows the simulation set-up. 


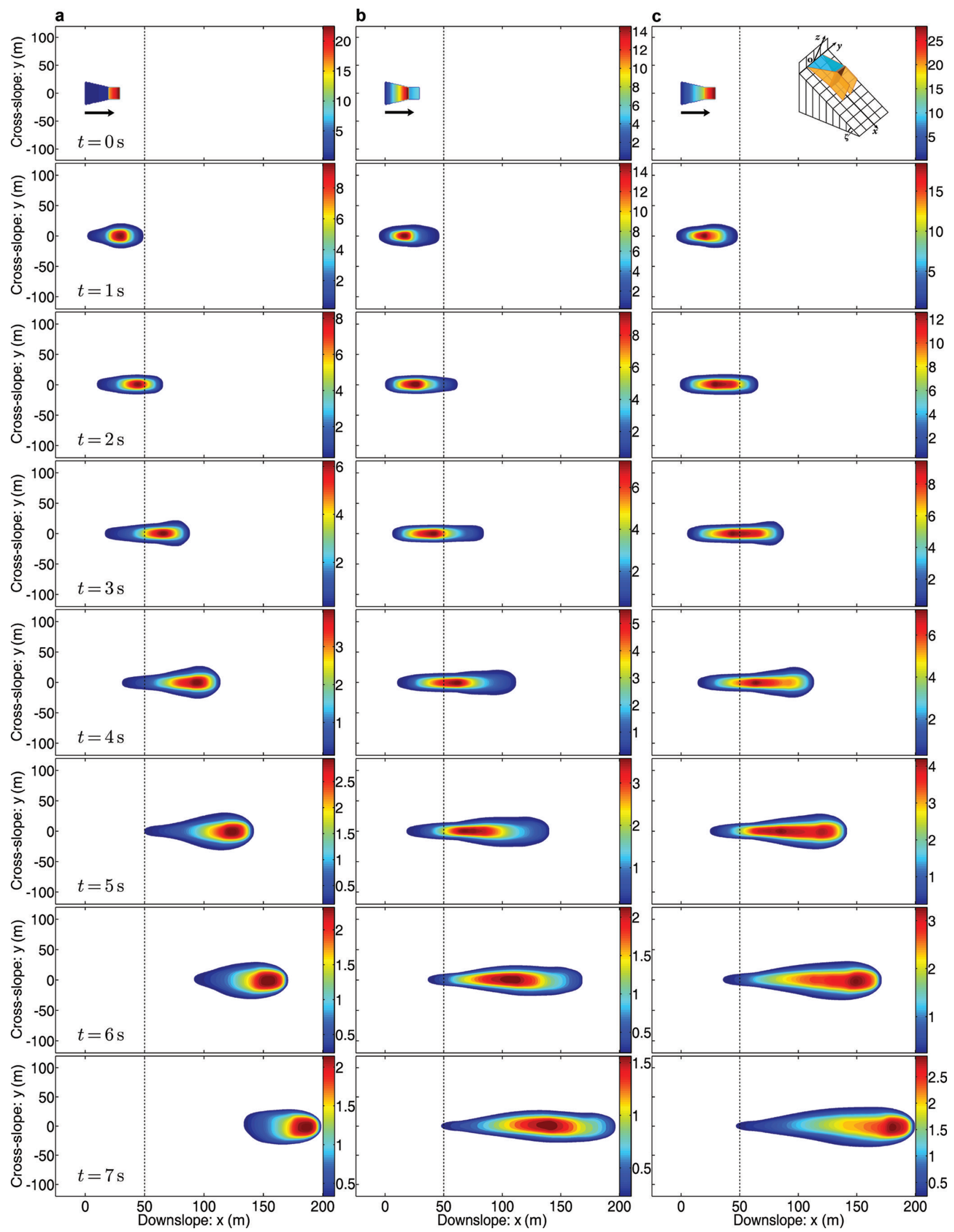

Fig. 4. Fan-type laterally expanding reservoir with lateral solid walls: evolution of (a) solid phase, (b) fluid phase and (c) total debris mixture at $t=0,1,2,3,4,5,6$ and $7 \mathrm{~s}$ when the triangular fan-shaped reservoir, bounded by non-deformable rigid vertical walls, follows a deformable moraine dam $(20 \mathrm{~m} \leq x \leq 29 \mathrm{~m})$. As soon as the dam breaks, the flow is accelerated in the laterally confined rectangular channel conduit $(29 \mathrm{~m} \leq x \leq 50 \mathrm{~m})$. The dashed line at $x=50 \mathrm{~m}$ indicates the conduit exit. Due to the larger amount of fluid material at the back, it takes longer for the reservoir to empty, thereby longer and thinner tails are formed than in Figure 3 , and the fluid and total debris plumes develop into comets with wide heads and long tails. The arrows in the top panels indicate the flow direction. Inset in top panel of (c) shows the simulation set-up. 
laterally deflected solid-rich frontal surge head of maximum density followed by relatively fluidized (more fluid than solid) material. The typical shape of the relative maximum shows that there is a solid-dominated mechanically strong part in the lateral levees and the frontal surge head and a fluid-rich dilute and relatively weak debris body at the rear (Major and Iverson, 1999; Iverson and Denlinger, 2001; Pudasaini and others, 2005; McArdell and others, 2007; Schneider and others, 2011; Johnson and others, 2012; Pudasaini, 2012; Braat, 2014; Pudasaini and Krautblatter, 2014). Such phenomena, as newly simulated here, are often observed in natural debris flows and GLOFs in high mountain torrents.

\subsubsection{Rectangular solid lateral walls}

Next, we change the upstream geometry and the lateral boundary condition. The walls of the lake (reservoir) are now solid and non-deformable, and the frontal dam is relatively longer $(20 \mathrm{~m} \leq x \leq 29 \mathrm{~m})$. The side-walls lie in $0 \mathrm{~m} \leq x \leq 50 \mathrm{~m}$, thus forming a rectangular conduit that contains the dam, the lake and a substantial portion of the channel downstream (Fig. 3). Thus, these lateral walls define a rectangular gully between mountain flanks. Other conditions are as in Section 3.3.1. The advantage here is that, as the initial triangular-wedge lake lies in $0 \mathrm{~m} \leq x \leq 29 \mathrm{~m}$, after break-off of the frontal moraine dam, the flow first accelerates over a substantial distance $(29 \mathrm{~m} \leq x \leq 50 \mathrm{~m})$ in the laterally confined rectangular channel conduit, then, as the flow exits the conduit, it can also expand laterally. Simulations are presented in Figure 3 for solid phase, fluid phase and the total debris depth evolutions.

As the frontal moraine dam is solid-rich and the rear of the lake is mostly fluid, the solid and fluid phases evolve quite differently. Since the lake and a portion of the downstream channel are laterally confined by almost vertical walls, after collapse of the frontal dam, on the one hand the solid material moves immediately downslope due to gravity and the pressure gradient (Fig. 3a), while on the other hand the fluid reservoir is also pressing the solid phase to move downslope. Therefore, although the solid phase has already begun to exit the conduit at $t=2 \mathrm{~s}$ (Fig. 3a), the fluid phase is still elongating in the downslope direction even at $t>3 \mathrm{~s}$ (Fig. 3b). Interestingly, as the debris mass exits the conduit, the solid and fluid phases and the total debris (Fig. 3c) all develop into a distinctive (pear- or bulb-like) extruding plume. During this time, the total debris also expands substantially across-slope resulting in an increasingly bulb-like structure. The solid-phase plume begins to develop at $t=2 \mathrm{~s}$ and continues until $t=4 \mathrm{~s}$. From $t=5$ to $t=7 \mathrm{~s}$, since the solid phase has now completely left the conduit, it is gradually expanding in the lateral direction too, and thus developing into a more ellipsoidal form as often observed in unconfined free-surface mass flows (Gray and others, 1999; Pudasaini and Hutter, 2007). Until $t=5 \mathrm{~s}$, the front to middle part of the solid phase is wide, while the rear is narrow. This is because the greater part of the solid is derived from the frontal moraine dam and initially there is much less solid in the reservoir.

The initial and subsequent solid deformations are fundamentally different. At the inception of flow, the frontal free-surface pressure gradient is the dominating force. Thus, during the initial stages of the deformation, the solid phase is quickly rarefied in the downslope direction and also slightly across-slope (because of the $85^{\circ}$ walls). After about $t=2 \mathrm{~s}$, the free-surface gradient decreases quickly. Now the flow is driven mainly by gravity. As the flow becomes shallower $(t \geq 2 \mathrm{~s})$, the tail also begins to move downslope, then both the front and the tail of the cascading solid phase accelerate. An important aspect here is the formation and propagation of the strong frontal head of solid from $t=3$ to $t=7 \mathrm{~s}$. Gradually, this head is pushed towards the front of the solid mass; the pushing is related to the dynamics of the following fluid phase, which we discuss below.

The fluid-phase dynamics (Fig. 3b) reveal other important features of GLOFs. Initially, the major part of the fluid is contained in the lake. The fluid is supported by the relatively wide and longer moraine dam in the front. So, since the conduit is extended further downslope, it takes relatively more time for the substantial amount of fluid to move. The major part of the fluid starts to move downslope after $t=2 \mathrm{~s}$. Until $t=3 \mathrm{~s}$ it still behaves as if it were flowing in the rectangular conduit. Although the fluid starts to exit the conduit after $t=3 \mathrm{~s}$, it begins to develop into a plume only from $t=4$ to $t=7 \mathrm{~s}$. In contrast to the solid phase (Fig. 3a), the extruding fluid plume is slightly narrower in the lateral direction and very elongated in the downslope direction. This can be explained because the major portion of the fluid was in the lake and the long rectangular channel was preventing the fluid from expanding laterally for quite a while. This resulted in a relatively long, thin and weak fluid tail from $t \geq 4 \mathrm{~s}$ to $t=7 \mathrm{~s}$. Nevertheless, the tail length decreased from $t=6$ to $t=7 \mathrm{~s}$, so, as the fluid was already accelerating substantially in the downslope direction, it could not disperse as much in the lateral direction. Importantly, contrary to the solid-phase evolution, the major portion of the fluid is relatively retarded to the back or the central part of the fluid. The major portion of the fluid (i.e. the relative maximum) lies mainly at the back until $t=5 \mathrm{~s}$, then it is shifted slightly to the centre-right from $t=6$ to $t=7 \mathrm{~s}$.

The overall dynamics are presented by the evolution of the total debris flow depth (Fig. 3c), which is the sum of the solid- and the fluid-phase depths (Fig. 3a and b). The total debris mixture evolution results from the dominant dynamics of each of the two phases. Interestingly, until $t=2 \mathrm{~s}$, it is more in the rectangular form. As in the solid phase, the extrusion of the debris-mixture plume begins at $t=3 \mathrm{~s}$. Afterwards, as the debris continues to exit the conduit, it develops continuously into a more pronounced and elongated plume, which also expands substantially in the lateral direction. The process continues until $t=7 \mathrm{~s}$ when the debris has already left the conduit. After $t=3 \mathrm{~s}$, when the debris material has become substantially thinner, both the front and the rear accelerate downslope. Since the maxima of the solid and fluid phase evolve differently, the maximum of the debris mixture also evolves in a way that captures the complementary characteristics of both the solid and fluid phases. Until $t=4 \mathrm{~s}$, the maximum depth of the debris lies from the back to the middle part of the debris body. A frontal surge head starts forming from $t=5 \mathrm{~s}$. By $t=6 \mathrm{~s}$, a strong solid-dominated surge head has developed, followed by a thin and weak fluid-rich tail. This surging process intensifies until $t=7 \mathrm{~s}$

The results presented in Figure 3 are fundamentally different from those presented in Figure 2 (Section 3.3.1). The differences result from the upstream channel geometry, initial configuration, material volume and boundary condition. Owing to the laterally flat geometry without boundary 
constraints, the flows in Figure 2 are wider than in Figure 3, in which the flow is laterally confined. Due to the lateral confinement, downslope momentum is dissipated less by lateral spreading, and due to the pressure from the channel (Pudasaini and others, 2005) the flow elongates and travels much farther downslope than in the laterally unconfined flows (Fig. 2). Further substantial differences are also seen in the geometrical evolution of the fronts and the tails between Figures 2 and 3.

\subsubsection{Fan-type laterally expanding lake with lateral solid walls}

Next we advance further by considering even more realistic initial configuration, channel geometry and boundary conditions. For this, the lake is made to become wider with distance upstream from the back of the dam (Fig. 4). The triangular fan-shaped lake is laterally bounded by nondeformable rigid walls that are almost vertical $\left(85^{\circ}\right)$. On one hand this increases the mass of the lake, while on the other it prevents lateral spreading beyond the walls. As in the previous flow configuration (Fig. 3), the conduit now extends downslope with two parallel walls from the back of the dam until $x=50 \mathrm{~m}$. This guides the flow to divert slightly towards the central line of the channel. The main idea here is to further analyze the effect of the initial, geometrical and boundary conditions on the flow dynamics.

The results for the evolution of the solid and fluid phases and the total debris mixture are presented in Figure $4 a, b$ and $\mathrm{c}$, respectively. The overall dynamics are qualitatively very close to those presented in Figure 3 (Section 3.3.2). Nevertheless, there are quantitative differences between Figures 3 and 4 . The fan shape of the lake tends to elongate substantially the evolving tails of the solid and fluid phases and total debris mixture. The larger lake takes longer to empty. Moreover, due to the larger amount of material, both solid and fluid phases and the total debris have more momentum and travel farther than in Figure 3. This leads to more developed and elongated bulb-like extruding plumes of solid ( $t \geq 2 \mathrm{~s}$ to $t=5 \mathrm{~s}$ ), fluid ( $t \geq 3$ to $t=7 \mathrm{~s}$ ) and debris mixture $(t \geq 3 \mathrm{~s}$ to $t=7 \mathrm{~s})$. Interestingly, due to the larger supply of fluid and greater emptying duration, both the fluid and total debris plumes developed into comets with wide heads and long tails. This was not as pronounced in Figure 3. Furthermore, there are many detailed and substantial dynamic differences in Figure 4 compared with Figure 3. These include the spreading and conduit exit process of the material, material distribution, form and thickness dynamics, development of the frontal heads, single and multiple surges, and the frontal surge and tail dynamics.

The simulations presented in Figures 2-4 reveal that the reservoir geometry, material volume, boundary conditions and channel geometry strongly influence the extruding and emptying processes. With respect to the real two-phase modelling and simulations, these are novel results in describing GLOF processes. As these results are in line with our physical intuition of two-phase flow dynamics about GLOFs, these results and simulation strategies can potentially be extended and applied to appropriately describing the lake- and reservoir-emptying process and subsequent flow, impact and inundation dynamics. This provides a means to develop evacuation plans and mitigation strategies in mountain valleys prone to debris flows, debris floods and GLOFs, including the Himalaya and the Alps.

\section{SUMMARY}

In order to simulate a GLOF, we have presented simulation results for two-phase mass flows down an inclined channel that allows the material to flow in a conduit and then to spread both downslope and across-slope. We considered three combinations of upstream channel geometry, boundary conditions, material volumes and initial glacial lake configurations with saturated frontal moraine dams. The boundary conditions include: idealized rectangular lateral walls that virtually collapse to trigger debris release; solid vertical lateral walls that prevent lateral spreading during the debris release; and a fan-shaped lake (or reservoir) with upslopewidening walls that prevent lateral spreading and divert the debris towards the central line of the slope. We discussed in detail the rapid collapse of the dam and emptying of the lake, leading to the extrusion of total-debris plumes.

Through simulations, completely different evolutions and fundamentally different dynamical behaviours of the solid and fluid phases have been presented. A frontal and lateral solid-rich levee, which is followed by a fluid-rich secondary surge, is formed in the total debris mixture evolution. The dynamics of the lake emptying, the extrusion of the debris plumes and the subsequent flows depend on the initial shape of the lake, conduit geometry, material volume and boundary conditions. Depending upon the proportion of solid and fluid, conduit geometry and boundary conditions, phase interactions and overall dynamics of the mixture, the real two-phase mass flow model and the simulation strategies can be extended and applied to a wide range of geophysical mass flows, including granular flows, snow and rock avalanches, and the flow of powders and grains in process industries, as well as debris flows in torrents and flash floods. This forms a basis for advanced hazard mitigation planning and enhancement of safety measures against potential geo-disasters. Nevertheless, for this, simulations must be performed for real flow events, which is not within the scope of this paper.

\section{ACKNOWLEDGEMENTS}

We thank the anonymous reviewers, Scientific Editor Nicolas Eckert and Chief Editor Graham Cogley for constructive comments that helped to improve the manuscript significantly. Shiva P. Pudasaini acknowledges the financial support provided by the German Research Foundation (DFG) through research project PU 386/3-1 'Development of a GIS-based open source simulation tool for modelling general avalanche and debris flows over natural topography', within a transnational research programme $\mathrm{D}-\mathrm{A}-\mathrm{CH}$.

\section{REFERENCES}

Awal R, Nakagawa $\mathrm{H}$, Fujita $\mathrm{M}$, Kawaike $\mathrm{K}$, Baba $\mathrm{Y}$ and Zhang $\mathrm{H}$ (2010) Experimental study on glacial lake outburst floods due to waves overtopping and erosion of moraine dam. Annu. Disaster Prev. Res. Inst. Kyoto Univ., 53B, 583-594

Bagnold RA (1954) Experiments on a gravity-free dispersion of large solid spheres in a Newtonian fluid under shear. Proc. R. Soc. London, Ser. A, 225, 49-63

Braat L (2014) Debris flows on Mars: an experimental analysis. (Master thesis, University of Utrecht)

Breien H, De Bkasio FV, Elverhoi A and Hoeg K (2008) Erosion and morphology of a debris flow caused by a glacial lake outburst flood, Western Norway. Landslides, 5, 271-280 (doi: 10.1007/ s10346-008-0118-3) 
Cageao PP, Turnbull B and Bartelt P (2013) Experiments on the dynamics of subaerial two-phase debris flows. Geophys. Res. Abstr., 15, EGU2013-9254-2

Chen CL (1988) Generalized viscoplastic modelling of debris flow. J. Hydraul. Res., 114(3), 237-258

Fernandez-Nieto ED, Bouchut F, Bresch D, Castro Daz MJ and Mangeney A (2008) A new Savage-Hutter type model for submarine avalanches and generated tsunami. J. Comput. Phys., 227(16), 7720-7754

Gray JMNT, Wieland M and Hutter K (1999) Gravity-driven free surface flow of granular avalanches over complex basal topography. Proc. R. Soc. London, Ser. A, 455, 1841-1874

Hungr O (1995) A model for the run out analysis of rapid flow slides, debris flows, and avalanches. Can. Geotech. J., 32, 610-623

Hutter K, Svendsen B and Rickenmann D (1996) Debris flow modelling review. Contin. Mech. Thermodyn., 8, 1-35

International Centre for Integrated Mountain Development (ICIMOD) (2011) Glacial lakes and glacial lake outburst floods in Nepal. International Centre for Integrated Mountain Development, Kathmandu

Iverson RM (1997) The physics of debris flows. Rev. Geophys., 35(3), 245-296

Iverson RM and Denlinger RP (2001) Flow of variably fluidized granular masses across three-dimensional terrain: 1. Coulomb mixture theory. J. Geophys. Res., 106(B1), 537-552

Johnson AM (1965) A model for debris flow. (PhD dissertation, Pennsylvania State University)

Johnson CG, Kokelaar BP, Iversion RM, Logan M, LaHusen RG and Gray JMNT (2012) Grainsize segregation and levee formation in geophysical mass flows J. Geophys. Res., 117, F01032 (doi: 10.1029/2011JF002185)

Kafle J (2014) Dynamic interaction between a two-phase submarine landslide and a fluid reservoir. (MPhil dissertation, Kathmandu University)

Kattel P (2014) Dynamics of quasi-three-dimensional and twophase mass flows. (MPhil dissertation, Kathmandu University)

Khattri KB (2014) Sub-diffusive and sub-advective viscous fluid flows in debris and porous media. (MPhil dissertation, Kathmandu University)

Lecomte I, Thollet I, Juliussen H and Hamran SE (2008) Using geophysics on a terminal moraine damming a glacial lake: the Flatbre debris flow case, Western Norway. Adv. Geosci., 14, 301-307

Major J and Iverson RM (1999) Debris-flow deposition: effects of pore-fluid pressure and friction concentrated at flow margins. Geol. Soc. Am. Bull., 110, 1424-1434
McArdell BW, Bartelt P and Kowalski J (2007) Field observations of basal forces and fluid pore pressure in a debris flow. Geophys. Res. Lett., 34, 2009-2039

Nessyahu H and Tadmor E (1990) Non-oscillatory central differencing for hyperbolic conservation laws. J. Comput. Phys., 87(2), 408-463

O'Brien JS, Julien PY and Fullerton WT (1993) Two-dimensional water flood and mud flow simulation. J. Hydraul. Eng., 119(2), 244-261

Pitman EB and Le L (2005) A two fluid model for avalanche and debris flows. Philos. Trans. R. Soc. A, 363(3), 1573-1601

Pokhrel PR (2014) General phase-eigenvalues for two-phase mass flows: supercritical and subcritical states. (MPhil dissertation, Kathmandu University)

Pudasaini SP (2012) A general two-phase debris flow model. J. Geophys. Res., 117, F03010 (doi: 10.1029/2011JF002186)

Pudasaini SP (2014) Dynamics of submarine debris flow and tsunami. Acta Mech., 225, 2423-2434 (doi: 10.1007/s00707014-1126-0)

Pudasaini SP and Hutter K (2003) Rapid shear flows of dry granular masses down curved and twisted channels. J. Fluid Mech., 495, 193-208

Pudasaini SP and Hutter K (2007) Avalanche dynamics: dynamics of rapid flows of dense granular avalanches. Springer, Berlin and New York

Pudasaini SP and Krautblatter M (2014) A two-phase mechanical model for rock-ice avalanches. J. Geophys. Res. Earth Surf., 119(10), 2272-2290 (doi: 10.1002/2014JF003183)

Pudasaini SP and Miller SA (2013) The hypermobility of huge landslides and avalanches. Eng. Geol., 157, 124-132

Pudasaini SP, Wang Y and Hutter K (2005) Modelling debris flows down general channels. Natur. Hazards Earth Syst. Sci., 5, 799-819

Savage SB and Hutter K (1989) The motion of a finite mass of granular material down a rough incline. J. Fluid Mech., 199, 177-215

Schneider D, Huggel C, Haeberli W and Kaitna R (2011) Unraveling driving factors for large rock-ice avalanche mobility. Earth Surf. Process. Landf., 36(14), 1948-1966

Takahashi T (1991) Debris flow. (IAHR-AIRH Monograph Series A) Balkema, Rotterdam

Takahashi T (2007) Debris flow: mechanics, prediction and countermeasures. Taylor and Francis, New York

Worni R, Stoffel M, Huggel C, Volz C, Casteller A and Luckman B (2012) Analysis and dynamic modelling of a moraine failure and glacier lake outburst flood at Ventisquero Negro, Patagonian Andes (Argentina). J. Hydrol., 444-445, 134-145 